\title{
F. Delmotte, M. Hubert, La Cité administrative de l'État. Schémas directeurs et action publique à Bruxelles
}

Les Cahiers de La Cambre Architecture n 8, Bruxelles, La Lettre Volée, 2009

\section{Mathieu Van Criekingen}

\section{(2) OpenEdition}

\section{Journals}

Édition électronique

URL : http://journals.openedition.org/belgeo/8774

DOI : $10.4000 /$ belgeo.8774

ISSN : 2294-9135

Éditeur :

National Committee of Geography of Belgium, Société Royale Belge de Géographie

Édition imprimée

Date de publication : 30 juin 2009

ISSN : 1377-2368

Référence électronique

Mathieu Van Criekingen, «F. Delmotte, M. Hubert, La Cité administrative de l'État. Schémas directeurs et action publique à Bruxelles », Belgeo [En ligne], 2 | 2009, mis en ligne le 21 mai 2013, consulté le 22 septembre 2020. URL : http://journals.openedition.org/belgeo/8774 ; DOI : https://doi.org/10.4000/ belgeo. 8774

Ce document a été généré automatiquement le 22 septembre 2020.

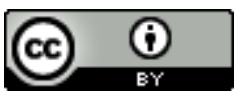

Belgeo est mis à disposition selon les termes de la licence Creative Commons Attribution 4.0 International. 


\section{F. Delmotte, M. Hubert, La Cité administrative de l'État. Schémas directeurs et action publique à Bruxelles}

Les Cahiers de La Cambre Architecture n 8, Bruxelles, La Lettre Volée, 2009

\section{Mathieu Van Criekingen}

\section{RÉFÉRENCE}

F. Delmotte, M. Hubert, “La Cité administrative de l'État. Schémas directeurs et action publique à Bruxelles", Les Cahiers de La Cambre Architecture, n8, Bruxelles, La Lettre Volée, 2009

1 Fruit d'un travail d'équipe mené aux Facultés Universitaires Saint-Louis, cet ouvrage témoigne d'un bel effort de décryptage des mutations récentes des pratiques de l'urbanisme à Bruxelles, avec un résultat assez stimulant. L'ouvrage porte essentiellement sur la mise en oeuvre, à partir de 2005, des premiers Schémas Directeurs, nouvel outil d'action publique en matière urbanistique dont le principe avait été introduit trois ans plus tôt dans le second Plan Régional de Développement (PRD). Les auteurs ne cachent pas une ambition de dresser un premier bilan de ce nouveau dispositif, démarche sûrement bienvenue étant donné la faible inclination des pouvoirs régionaux bruxellois à (faire) évaluer de manière critique ses propres outils.

2 L'ouvrage replace utilement l'émergence des Schémas Directeurs dans le contexte, non spécifique à Bruxelles, de transformation des instruments d'action urbanistique, allant jusqu'à parler de "changement d'ère" (p. 300). Il est ici question de l'émergence de dispositifs voulus aptes à mettre en œuvre une planification territoriale à la fois plus stratégique (ou "visionnaire") et plus opérationnelle (ou "par projets") que les outils classiques de planification que sont les plans fixant réglementairement les affectations des sols. Sur le fond, cette évolution est indissociable de la montée en puissance du 
référentiel des "grands projets urbains" et des "partenariats publics-privés" dans les politiques urbaines contemporaines, sensible, à Bruxelles, depuis le début des années 2000. Les nouveaux outils et structures d'urbanisme opérationnel (la nouvelle Agence de Développement Territorial, notamment) visent précisément à faciliter la mise en oeuvre de ces projets, dont le récent Plan de Développement International de Bruxelles (PDI) offre un catalogue devenu classique (centres de congrès, musée, complexe commercial, ensembles de bureaux, etc.).

3 L'ouvrage s'appuie sur un important travail d'observation, par moment quasi ethnographique, des jeux d'acteurs, saisis à différents moments forts (et publics) de l'élaboration de quatre Schémas Directeurs - i.e. "Botanique" (l'ex-Cité Administrative de l'Etat, Tour des Finances exclue), “Quartier Européen", “Gare de l'Ouest" et "Tour et Taxis". Cet angle d'analyse met logiquement en exergue des questionnements sur les pratiques de participation de différents types d'acteurs (auteur de projets, propriétaires des sites, développeurs immobiliers, autorité publiques régionales et communales, groupes d'habitants) abordant en cela une dimension primordiale de l'outil Schéma Directeur. En effet, comme le relèvent justement les auteurs, cet outil se positionne nettement dans le champ de la "gouvernance urbaine" dès lors qu'il vise essentiellement à la (co-)production d'un consensus entre acteurs aux intérêts au moins partiellement divergents mais que le dispositif tente de positionner comme "partenaires".

4 De ce travail qualitatif fouillé émergent une série d'enseignements transversaux. D'une part, l'ouvrage met bien en exergue le rôle de la "mouvance associative militante de l'architecture belge contemporaine" (p. 77), soit une élite émergente proche des cabinets ministériels et combinant les registres de l'action associative, de la pratique professionnelle et de l'enseignement supérieur. Un chapitre de l'ouvrage est d'ailleurs une "vue de l'intérieur" (p. 102) de l'un d'entre eux (B. Moritz, à la fois membre du collectif Disturb, auteur de projet des schémas directeurs "Botanique" et "Tour \& Taxis" via son bureau d'étude et enseignant à La Cambre). D'autre part, l'analyse montre clairement qu'il n'est pas permis de confondre "participation citoyenne" et "démocratie", ne fût-ce que parce que la participation repose sur une sélection non mise en débat d'acteurs ('stakeholders') considérés comme a priori comme légitimes. La position d'associations comme Inter-Environnement Bruxelles (IEB) et le Brusselse Raad voor het Leefmilieu (BRAL) dans le dispositif est révélatrice de cet écart. En effet, IEB et BRAL y sont impliqués en tant que prestataires de services pour le compte des autorités régionales (qui les rétribue pour ce faire), le service en question consistant à relayer les préoccupations des habitants et à expliquer en retour à ceux-ci les contraintes et les demandes des autres acteurs. De la sorte, IEB et BRAL sont amenés à mettre de côté les dimensions critiques de leurs actions, qui ont nourri par le passé nombre de luttes urbaines, dont les dispositifs de participation en matière urbanistique sont précisément un héritage. Enfin, l'ouvrage met bien en évidence le principal nœud problématique du dispositif, à savoir l'indéfinition de l'objet de la concertation : qu'estce qui peut être influencé, rejeté ou modifié par l'issue des débats entre les "partenaires" - et qu'est-ce qui est non négociable, fixé dès le départ, intouchable ? Ces différents éléments amènent les auteurs à conclure à "un essai de gouvernance non abouti" (p. 303) appuyé sur "une ambition démocratique mal définie" (p. 305) pour un outil au "futur incertain" (p. 308). 
5 Enfin, si l'ouvrage comporte une faiblesse, elle se situe, à mon sens, dans le relatif manque d'approfondissement de l'interprétation du "changement d'ère" pointé par les auteurs. Le risque est ici d'aboutir à une relative déconnexion entre discussion sur les outils, d'une part, et analyse des objectifs politiques que ceux-ci sont censés mettre en œuvre (i.e. renforcer l'attractivité des territoires), d'autre part. 